\title{
Comorbid Chronic Diseases and Health-related Quality of Life in the Obese Population: a Longitudinal Analysis of a Nationally Representative Household Survey in Australia
}

Syed Afroz Keramat ( $\square$ afroz.keramat@usq.edu.au )

Khulna University https://orcid.org/0000-0001-8747-9891

Khorshed Alam

University of Southern Queensland

Bright Opoku Ahinkorah

University of Technology Sydney

Richard Gyan Aboagye

University of Health and Allied Sciences

Monidipa Saha

Americcan International University-Bangladesh

Nandeeta Samad

North South University

Jeff Gow

University of Southern Queensland

Stuart J. H. Biddle

University of Southern Queensland

Abdul-Aziz Seidu

James Cook University

\section{Research Article}

Keywords: Comorbid chronic diseases, HRQoL, PCS, MCS, SF-6D, Australia, HILDA

Posted Date: March 22nd, 2021

DOI: https://doi.org/10.21203/rs.3.rs-314009/v1

License: (c) (i) This work is licensed under a Creative Commons Attribution 4.0 International License. Read Full License 


\section{Abstract}

\section{Objective}

This study aims to examine the relationship between nine comorbid chronic conditions and HRQoL separately, along with the number of chronic diseases among the Australian obese population.

\section{Methods}

Data for this study were sourced from three waves (waves 9, 13 and 17) of the Household, Income and Labour Dynamics in Australia (HILDA) survey. The paper studies 9,444 person-year observations from 5,524 individuals over the years 2009, 2013, and 2017. The outcome variable of HRQoL was measured through the 36-Item Short Form Health Survey (SF-36), and the main variables of interest were nine chronic conditions and the number of chronic diseases. Generalized estimating equations (GEE) were used to test the association between comorbid chronic diseases and HRQoL.

\section{Results}

This study found a negative relationship between the number of comorbid chronic conditions and sub-scale, summary measures, and health utility index of the SF-36. Obese adults with 1, 2, 3, and 3+ comorbid chronic diseases scored lower points on the SF-36 physical component summary $(b=-2.83, b=-7.37, b=-11.15, b=-14.29$, respectively), mental component summary ( $b=-1.46, b=-2.34, b=-3.66$, and $b=-6.34$, respectively), and in the short-form sixdimension utility index (SF-6D) scale ( $b=-0.030, b=-0.063, b=-0.099$, and $b=-0.138$, respectively) compared to obese peers without comorbid chronic diseases. The number of chronic conditions was associated with reductions in the score of all eight dimensions of the SF-36. Obese people with any of the nine studied comorbid chronic diseases (heart disease, circulatory disease, hypertension, type 1 diabetes, type 2 diabetes, asthma, bronchitis, arthritis, and cancer) were associated with lower HRQoL compared to peers without that particular comorbid chronic disease.

\section{Conclusions}

Comorbid chronic diseases in obese individuals are associated with lower HRQoL. Increasing the number of comorbid chronic conditions is associated with a further reduction in all dimensions and summary measures of the SF- 36 . The findings, therefore, call for improved holistic management of obesity and interventions to reduce obesity-related comorbidities to improve HRQoL of obese Australian.

\section{Introduction}

Overweight and obesity are rapidly growing public health problems affecting many countries worldwide. Among the adult population, in 2016, more than 1.9 billion adults were overweight globally, of which 650 million were obese [1]. In Australia, obesity has increased from 18.5-27.9\% between 1995 and 2015 [2]. Two-thirds (67\%, 12.5 million) of Australian adults were either overweight or obese in 2017-18 [3], and adult obesity prevalence was projected to increase from $19 \%$ in 1995 to $35 \%$ by 2025 [2].

Quality of life broadly refers to the extent to which an individual can function successfully in daily life and their perceived well-being across physical, emotional, and social structures [4, 5]. Obesity is associated with increased comorbidity, mortality and reduced health-related quality of life (HRQoL) [6-10]. The health burden among individuals with raised body mass index (BMI) is becoming concerning, especially in those with co-occurring chronic conditions $[11,12]$. The relationship between BMI and HRQoL has been investigated in several population-based studies and have 
confirmed a negative association between BMI and self-perceived quality of life, with a higher risk of poorer HRQoL in overweight and obese persons [6, 13-17]. Further, obese persons report pain which has been considered the most significant impairment to HRQoL $[13,15,18]$. Moreover, overweight and obese people experience higher psychological distress, which is another considerable impairment in their HRQoL $[15,19]$. Several studies across diverse geographical locations have reported that comorbid chronic diseases are associated with poor quality of life. For instance, earlier studies found that overweight or obese individuals often report physical, mental, and social relationship problems [2024]. Of those reporting poor HRQoL, the highest burden was found among those with multiple comorbid chronic conditions [25]. Other empirical studies have reported poor HRQoL among persons with comorbid or multimorbid diseases [26-28].

HRQoL among obese individuals is understudied, with only a few empirical studies focused on establishing the association between comorbidities and quality of life. Two studies have reported that overweight and obesity were associated with low or poor HRQoL $[16,29]$. However, a recent study has not found a statistically significant association between HRQoL (measured by SF-6D) and comorbid chronic diseases in the Australian general population [7]. The discrepancy in the relationship between comorbid conditions and HRQoL in the existing literature warrants further investigation to draw robust conclusions on the longitudinal relationship between comorbidity and HRQoL in the obese population. Therefore, this paper aims to examine the associations between comorbid chronic diseases and HRQoL among the Australian obese population. This is a novel study that provides a significant opportunity to advance the understanding of the relationship between nine comorbid chronic diseases and HRQoL in the obese population separately, along with the number of comorbidities. The study will provide insights into the need for measures to prevent overweight and obesity, manage those with comorbid conditions, and prevent further development of comorbidities among overweight and obesity with a view to improving HRQoL.

\section{Methodology}

\section{Data Source and Sample selection}

This study's data were sourced from the Household, Income and Labour Dynamics in Australia (HILDA) survey, a nationally representative longitudinal study of the Australian population. The survey collects information annually on many aspects of life, such as wealth, labour market outcomes, household and family relationships, fertility, health and education. The survey was started in 2001 , and a multistage sampling approach was used to select an initial sample of households. At first, 488 Census Collection Districts (CD) were sampled with a probability proportional to size sampling technique; each consists of 200-250 households approximately across Australia. Secondly, from each of the CDs, a sample of 22-34 dwellings was selected randomly. Finally, up to three households from each dwelling were selected that results in the selection of a total of 12,252 households. Individuals aged 15 years or older residing in each household were included in the sample. The sample was expanded over time by including any child born or adopted by groups of respondents or by any new household member resulting from adjustments of the originating households' composition. Therefore, the survey follows the lives of more than 17,000 Australian adults annually.

This study utilized three waves of data: wave 9 (2009), 13 (2013) and 17 (2017) from the HILDA survey, spanning a period of nine years. The main reason for selecting these three waves is that data on comorbid chronic conditions were available only in these waves. This study restricted the sample to only obese adults aged 15 years or over. Missing observations on the outcome (dimensions of HRQoL) and main variables of interest (chronic diseases) were excluded from subsample analyses. After adjusting the inclusion and exclusion criteria, the final analytic sample consists of 9,444 person-year observations from 5,524 unique respondents.

\section{Outcome variable}


The outcome of interest in the present analysis is the health-related quality of life (HRQoL). HRQoL was measured through the RAND 36-Item Short Form Survey Instrument (SF-36). The SF-36 health survey is made up of 36 questions that cover eight dimensions: physical functioning (PF), role physical (RP); bodily pain (BP), general health $(\mathrm{GH})$, vitality (VT), social functioning (SF); role emotional (RE); and mental health (MH). For example, the physical functioning dimension was assessed by ten questions, and each question has three levels (Yes, limited a lot; Yes, limited a little; and No, not limited at all). These levels were scaled as 1, 2, and 3 and thus, summed values lie between 10 to 30 . This computed value was further transformed into a 0-100 scale. Similarly, each of the eight dimensions' score scale ranged from 0 to 100, wherein 0 represents the worst and 100 represents the best health status. It is important to note that SF36 does not consider the trade-offs among the eight dimensions. It means each dimension is equally important in describing the health states. Two summary measures of quality of life (QoL): physical component summary (PCS), and mental component summary (MCS) that reflect the physical and mental health-related quality of life, respectively, were derived from the SF-36 score. The summary scores, PCS and MCS, were calculated using the recommended scoring algorithms for Australians (1995 reference) and standardized by linear Z-score transformation with a mean of 50 and standard deviation (SD) of 10. The values of PCS and MCS ranged from 4.54 to 76.09 and from -1.21 to 76.19, respectively, with higher scores indicating better QoL [5].

Another instrument that is widely used in the economic evaluation as a measure of HRQoL is SF-6D. The SF-6D utility index can be derived from the SF-36 score and places health states in a scale that ranges from 0 to 1 . The value 1 indicates full health (all the eight dimensions at the best level), and 0 shows the worst health (equivalent to death).

\section{Exposure variables}

In the present analyses, comorbid chronic diseases are considered as the main exposure variables. This study assessed nine self-reported chronic diseases: heart disease, circulatory disease, hypertension, type 1 diabetes, type 2 diabetes, asthma, bronchitis, arthritis, and cancer. The HILDA survey collects information on an individual's chronic disease status by asking the question: 'have you ever been told by a medical practitioner that you have been diagnosed with a serious illness or medical conditions'. The responses were taken in binary form: an answer of zero means no, and one means yes. The variable number of comorbid chronic disease is constructed by summing up the nine studied chronic diseases. The variable was categorized into five: 0 (having no chronic condition), 1 (having only one chronic condition), 2 (having two of the studied chronic diseases), 3 (having three of the studied chronic diseases) and 3+ (having more than three of the studied chronic diseases).

\section{Other Covariates}

A set of socio-demographic and behavioural characteristics were included in the study as potential confounders. All the explanatory variables were categorized using dummies. Socio-demographic factors include age (15-25, 26-45, 46-60, and over 60 years); gender (male, and female); civil status (single [separated, divorced, widowed or never married], married [legally married], de-facto [in a de-facto relationship]); education (year 12 or below, certificate courses [certificate III or IV], university qualifications [undergraduate degree, degree with honours, advanced diploma or diploma, masters, doctorate, graduate diploma or graduate certificate]; household income (measured through OECD equivalence scale and categorized into quintiles of 1 to 5); indigenous status (non-indigenous, and Aboriginal or Torres Strait Islander); and location (major city, regional city [inner and outer regional], remote areas [remote or very remote areas]). Behavioural characteristics include smoking status (never smoked, ex-smoker, current smoker); alcohol consumption (never drink, ex-drinker, only rarely to 3 days per week, 3+ days per week); and physical activity that lasts at least 30 minutes (not at all to $<1$ per week, 1-3 times per week, $\geq 4$ times per week).

\section{Statistical analysis}

Page $4 / 19$ 
The authors constructed an unbalanced longitudinal data set consisting of 9,444 person-year observations of 5,524 unique participants by linking de-identified individuals' records wherein respondent information appeared more than once (up to three times). The current analyses report the pooled descriptive statistics as mean (SD) for continuous variables and percentages with $95 \%$ confidence intervals (Cls) for categorical variables.

This study fitted multivariate regression models to explore the relationship between comorbid chronic diseases and HRQoL. The regression models take the following form:

$$
H R Q o L_{i t}=\beta_{0}+\beta_{1} C D_{i t}+\beta_{2} X_{i t}+\varepsilon_{i t}
$$

In equation 1, represents the summary measures, health utility index, and a particular dimension of SF-36 representing respondents' QoL. CD is the key variables of interests that capture the presence of comorbid chronic diseases in the respondents, $\mathrm{X}$ is a vector of control variables, is the error term, and subscripts $\mathrm{i}$ refer to individual and $\mathrm{t}$ indicates periods.

This study constructed ten different models, defined by the primary variables of interest: number of comorbid chronic diseases, solely heart disease, circulatory disease exclusively, solely hypertension, solely type 1 diabetes, solely type 2 diabetes, solely asthma, solely bronchitis, solely arthritis, and solely cancer. The reference category was always the absence of the comorbid chronic diseases. All models were adjusted for age, gender, civil status, education, equivalized household income, labour force status, race, place of living, smoking status, alcohol consumption, and physical activity.

This study deployed the Generalized Estimating Equation (GEE) to estimate the effects of comorbid chronic diseases on HRQoL. A significant advantage of using the GEE technique is that it provides unbiased estimates of populationaveraged regression coefficients when the data's correlation structure is misspecified. A $p$-value of less than 0.05 was considered statistically significant, and the regression results were reported for three levels of $P<0.001,<0.01$, and $<0.05$. All analyses were conducted using STATA version 16.

\section{Results}

Table 1 shows the pooled summary statistics for the 9,444 Australian adults. The mean score for the eight domains of the SF-36 were 76.35 (SD = 25.60) for PF, $71.16(S D=40.06)$ for RP, $78.92(S D=36.43)$ for $R E, 78.33(S D=25.53)$ for $\mathrm{SF}, 72.30$ (SD = 18.36) for $\mathrm{MH}, 54.94(\mathrm{SD}=20.71)$ for $\mathrm{VT}, 65.87(\mathrm{SD}=25.47)$ for $\mathrm{BP}$, and 60.57 (SD = 21.48) for GH. The mean component summary measures (PCS and MCS) and health utility index (SF-6D) derived from the SF-36 were $45.78 \pm 11.38,47.72 \pm 11.26$, and $0.73 \pm 0.13$ (mean \pm SD), respectively. Among the study sample, over one quarter $(27 \%)$ have at least one chronic condition, followed by two (15\%), three (7\%), and more than three (4\%) comorbid chronic diseases. The most common comorbid chronic disease among the obese adults was hypertension (29\%), followed by arthritis (24\%), asthma (14\%), type 2 diabetes (10\%), and heart disease (6\%).

The results also reveal that almost one-fourth of the participants were over sixty years (25\%), over half were female (55\%), and married (53\%). Of the total, $18 \%$ had university qualifications, $61 \%$ were employed, $96 \%$ were nonindigenous, $61 \%$ lived in major cities, $19 \%$ were current smoker, $22 \%$ drunk over three days a week, and over one third (36\%) do not perform physical activities.

\section{Table 1. Pooled characteristics of study participants and subjective health scores}




\begin{tabular}{|c|c|c|}
\hline Variables & $\mathbf{n}$ & Mean (SD) / \% (95\% Cl) \\
\hline \multicolumn{3}{|c|}{ SF-36 domain scores [Mean (SD)] } \\
\hline Physical functioning (PF) & 9,444 & $76.35(25.60)$ \\
\hline Role physical (RP) & 9,444 & $71.16(40.06)$ \\
\hline Role emotional (RE) & 9,444 & $78.92(36.43)$ \\
\hline Social functioning (SF) & 9,444 & $78.33(25.53)$ \\
\hline Mental health $(\mathrm{MH})$ & 9,444 & $72.30(18.36)$ \\
\hline Vitality (VT) & 9,444 & $54.94(20.71)$ \\
\hline Bodily pain (BP) & 9,444 & $65.87(25.47)$ \\
\hline General health $(\mathrm{GH})$ & 9,444 & $60.57(21.48)$ \\
\hline \multicolumn{3}{|c|}{ SF-36 component summary scores [Mean (SD)] } \\
\hline PCS & 9,444 & $45.78(11.38)$ \\
\hline MCS & 9,444 & $47.72(11.26)$ \\
\hline SF-6D & 9,444 & $0.73(0.13)$ \\
\hline \multicolumn{3}{|c|}{ Number of comorbid chronic diseases (from the study checklist) } \\
\hline 0 & 4,452 & $47.14(46.14-48.15)$ \\
\hline 1 & 2,556 & $27.06(26.18-27.97)$ \\
\hline 2 & 1,400 & $14.82(14.12-15.56)$ \\
\hline 3 & 673 & $7.13(6.62-7.66)$ \\
\hline $3+$ & 363 & $3.84(3.47-4.25)$ \\
\hline \multicolumn{3}{|l|}{ Heart disease } \\
\hline No & 8,869 & $93.91(93.41-94.38)$ \\
\hline Yes & 575 & $6.09(5.62-6.59)$ \\
\hline \multicolumn{3}{|l|}{ Circulatory disease } \\
\hline No & 9,112 & $96.48(96.09-96.84)$ \\
\hline Yes & 332 & $3.52(3.16-3.91)$ \\
\hline \multicolumn{3}{|l|}{ Hypertension } \\
\hline No & 6,677 & 70.7 (69.77-71.61) \\
\hline Yes & 2,767 & $29.3(28.39-30.23)$ \\
\hline \multicolumn{3}{|l|}{ Type 1 diabetes } \\
\hline No & 9,311 & 98.59 (98.33-98.81) \\
\hline Yes & 133 & $1.41(1.19-1.67)$ \\
\hline Type 2 diabetes & & \\
\hline
\end{tabular}




\begin{tabular}{|c|c|c|}
\hline No & 8,472 & 89.71 (89.08-90.3) \\
\hline Yes & 972 & 10.29 (9.7-10.92) \\
\hline \multicolumn{3}{|l|}{ Asthma } \\
\hline No & 8,088 & 85.64 (84.92-86.33) \\
\hline Yes & 1,356 & $14.36(13.67-15.08)$ \\
\hline \multicolumn{3}{|l|}{ Bronchitis } \\
\hline No & 9,206 & 97.48 (97.14-97.78) \\
\hline Yes & 238 & $2.52(2.22-2.86)$ \\
\hline \multicolumn{3}{|l|}{ Arthritis } \\
\hline No & 7,176 & 75.98 (75.11-76.84) \\
\hline Yes & 2,268 & $24.02(23.16-24.89)$ \\
\hline \multicolumn{3}{|l|}{ Cancer } \\
\hline No & 9,103 & 96.39 (95.99-96.75) \\
\hline Yes & 341 & $3.61(3.25-4.01)$ \\
\hline \multicolumn{3}{|l|}{ Age } \\
\hline $15-25$ years & 1,001 & 10.6 (9.99-11.24) \\
\hline $26-45$ years & 3,175 & 33.62 (32.67-34.58) \\
\hline $46-60$ years & 2,903 & $30.74(29.82-31.68)$ \\
\hline$>60$ years & 2,365 & $25.04(24.18-25.93)$ \\
\hline \multicolumn{3}{|l|}{ Gender } \\
\hline Male & 4,270 & $45.21(44.21-46.22)$ \\
\hline Female & 5,174 & $54.79(53.78-55.79)$ \\
\hline \multicolumn{3}{|l|}{ Civil Status } \\
\hline Single & 3,487 & 36.92 (35.95-37.9) \\
\hline Married & 4,998 & $52.92(51.91-53.93)$ \\
\hline De-facto & 959 & 10.15 (9.56-10.78) \\
\hline \multicolumn{3}{|l|}{ Education } \\
\hline Year 12 and below & 4,281 & $45.33(44.33-46.34)$ \\
\hline Certificate courses & 3,428 & $36.3(35.33-37.27)$ \\
\hline University qualifications & 1,735 & 18.37 (17.6-19.17) \\
\hline \multicolumn{3}{|l|}{ Household income quintile } \\
\hline Quintile 1 & 1,889 & $20(19.21-20.82)$ \\
\hline Quintile 2 & 1,889 & $20(19.21-20.82)$ \\
\hline
\end{tabular}




\begin{tabular}{|c|c|c|}
\hline Quintile 3 & 1,889 & $20(19.21-20.82)$ \\
\hline Quintile 4 & 1,889 & $20(19.21-20.82)$ \\
\hline Quintile 5 & 1,888 & 19.99 (19.2-20.81) \\
\hline \multicolumn{3}{|l|}{ Labour force status } \\
\hline Employed & 5,803 & $61.45(60.46-62.42)$ \\
\hline Unemployed & 341 & $3.61(3.25-4.01)$ \\
\hline Not in the labour force & 3,300 & 34.94 (33.99-35.91) \\
\hline \multicolumn{3}{|l|}{ Indigenous status } \\
\hline Non-indigenous & 9,076 & $96.1(95.69-96.48)$ \\
\hline Aboriginal/Torres Strait Islander & 368 & $3.9(3.52-4.31)$ \\
\hline \multicolumn{3}{|l|}{ Location } \\
\hline Major city & 5,741 & $60.79(59.8-61.77)$ \\
\hline Regional & 3,544 & $37.53(36.55-38.51)$ \\
\hline Remote & 159 & $1.68(1.44-1.96)$ \\
\hline \multicolumn{3}{|l|}{ Smoking status } \\
\hline Never smoked & 4,500 & $47.65(46.64-48.66)$ \\
\hline Ex-smoker & 3,184 & $33.71(32.77-34.67)$ \\
\hline Current smoker & 1,760 & $18.64(17.86-19.43)$ \\
\hline \multicolumn{3}{|l|}{ Alcohol consumption } \\
\hline Never drink & 898 & $9.51(8.93-10.12)$ \\
\hline Ex-drinker & 913 & $9.67(9.09-10.28)$ \\
\hline Only rarely to 3 days/week & 5,538 & $58.64(57.64-59.63)$ \\
\hline $3+$ days/week & 2,095 & $22.18(21.36-23.03)$ \\
\hline \multicolumn{3}{|c|}{ Physical activity that lasts at least $\mathbf{3 0} \mathrm{min}$} \\
\hline Not at all to $<1 /$ week & 3,392 & $35.92(34.96-36.89)$ \\
\hline 1-3 times/week & 3,701 & $39.19(38.21-40.18)$ \\
\hline$\geq 4$ times/week & 2,351 & $24.89(24.03-25.78)$ \\
\hline
\end{tabular}

Table 2 presents the mean values of each of the eight dimensions of SF-36, the summary measures and the health utility index by the number of comorbid chronic diseases. As can be seen, the mean score for all SF-36 dimensions/subscales, composite measures, and health utility index decline with a higher number of chronic diseases. For example, obese people with more than three comorbid chronic diseases had the lowest scores than their counterparts with zero, one, two and three chronic conditions. The respective mean PCS, MCS, and SF-6D scores among the study sample with over three chronic diseases $(29.48 \pm 9.78,43.86 \pm 11.76$, and $0.59 \pm 0.11$, respectively) were much lower than peers without the comorbid chronic disease $(50.77 \pm 8.14,48.02 \pm 10.76$, and $0.76 \pm 0.11$, respectively). 
Table 2. The SF-36 subscale scores and the summary measures by number of chronic conditions

\begin{tabular}{|c|c|c|c|c|c|}
\hline \multirow{3}{*}{$\begin{array}{l}\text { The SF-36 subscale } \\
\text { and summary measures }\end{array}$} & \multicolumn{5}{|c|}{ Number of comorbid chronic diseases } \\
\hline & 0 & 1 & 2 & 3 & $3+$ \\
\hline & $($ Mean $\pm S D)$ & $($ Mean \pm SD $)$ & $($ Mean \pm SD $)$ & $($ Mean \pm SD $)$ & $($ Mean $\pm S D)$ \\
\hline Physical functioning & $86.18(19.64)$ & $77.36(22.83)$ & $64.08(25.89)$ & $51.21(26.98)$ & $42.57(25.29)$ \\
\hline Role physical & $84.61(30.84)$ & $72.45(38.93)$ & $54.00(43.37)$ & $38.41(42.25)$ & $24.06(35.83)$ \\
\hline Role emotional & $84.72(31.63)$ & $79.75(35.39)$ & $72.95(40.29)$ & $64.14(43.25)$ & $52.34(45.31)$ \\
\hline Social functioning & $83.82(22.15)$ & $79.34(24.46)$ & $72.38(27.26)$ & $63.84(29.29)$ & $53.62(27.57)$ \\
\hline Mental health & $73.56(17.50)$ & $72.22(18.74)$ & $71.82(18.86)$ & $68.74(19.77)$ & $65.89(18.91)$ \\
\hline Vitality & $58.51(19.66)$ & $55.24(20.70)$ & $51.31(20.96)$ & $46.50(20.28)$ & $38.76(18.60)$ \\
\hline Bodily pain & $75.40(21.12)$ & $65.36(24.09)$ & $54.04(24.77)$ & $45.00(25.08)$ & 36.79 (21.97) \\
\hline General health & $67.47(18.30)$ & 60.99 (19.73) & $53.06(21.65)$ & $43.60(21.88)$ & 33.50 (19.79) \\
\hline PCS & 50.77 (8.14) & $46.06(10.12)$ & 39.38 (11.44) & $33.83(11.40)$ & 29.48 (9.78) \\
\hline MCS & $48.02(10.76)$ & $47.83(11.40)$ & 48.05 (11.81) & $46.67(12.14)$ & $43.86(11.76)$ \\
\hline SF-6D & $0.76(0.11)$ & $0.73(0.12)$ & $0.69(0.13)$ & $0.64(0.12)$ & $0.59(0.11)$ \\
\hline
\end{tabular}

Figure 1 depicts the composite summary scores (PCS and MCS) of the SF-36 by age and gender. It is observed that the PCS score declines with age. Mean PCS score ranged from 52.19 (15-25 years) to 39.48 (60+ years) in males and from 51.26 (15-25 years) to 36.82 (60+ years) in females. However, the MCS score of the study participants went up with age. The mean MCS score ranged from 47.80 (15-25 years) to 50.59 (60+ years) in males and from 42.89 (15-25 years) to $50.83(60+$ years $)$ in females.

Figure 2 offered the visual representation of the health utility index (SF-6D) by age and gender. The figure shows that the study participant's overall health state slightly declines with age and is generally lower in females. The mean SF-6D score ranged from 0.77 (26-45 years) to 0.70 (60+ years) in males and from 0.72 (15-25 years) to 0.69 (60+ years) in females.

Table 3 displays the association between comorbid chronic diseases and the three summary measures (PCS, MCS and SF-6D) of the SF-36. The estimated coefficients of the number of comorbid chronic diseases and individual chronic diseases concerning the summary measures and health utility index were reported in models 1 to 3 . Models 1 and 2 indicate that obese people with a higher number of comorbid chronic diseases scored significantly worse on both PCS and MCS scores than obese people with zero comorbid chronic diseases. Obese people with 1, 2, 3, and 3+ comorbid chronic diseases scored $3(b=-2.83), 7(b=-7.37), 11(b=-11.15)$, and $14(b=-14.29)$ points/units lower on the PCS indicator, and $1(b=-1.46), 2(b=-2.34), 4(b=-3.66)$, and $6(b=-6.34)$ units lower on the MCS indicator, respectively, compared with obese people without comorbid chronic diseases. Models 1 and 2 also report the effects of individual chronic diseases on both PCS and MCS indicators. The result showed that obese people with any of the nine chronic diseases had significantly lower scores on both PCS and MCS indicators. For example, the effect of having cancer in obese people on both PCS $(b=-4.08)$ and MCS $(b=-2.27)$ were lower than counterparts without cancer. 
On the SF-6D scale, obese adults with 1, 2, 3 and more than 3 comorbid chronic diseases scored $3(b=-0.03), 6(b=$ $-0.063), 10(b=-0.099)$, and $14(b=-0.138)$ percentage points lower, respectively, compared with obese peers who do not have any chronic disease (model 3). Similarly, the results also showed that obese people having any type of the studied chronic diseases (heart disease, circulatory disease, hypertension, type 1 diabetes, type 2 diabetes, asthma, bronchitis, arthritis, and cancer) scored lower on the SF-6D scale compared with obese people without that particular chronic disease. For example, obese adults with heart disease scored $6(b=-0.058)$ percentage points lower on the SF$6 \mathrm{D}$ scale than their counterparts without heart disease.

\section{Table 3. GEE estimates of the relationship between chronic conditions and HRQOL}




\begin{tabular}{|c|c|c|c|}
\hline \multirow[t]{2}{*}{ Variables } & Model 1 & Model 2 & Model 3 \\
\hline & PCS, $\beta(95 \% \mathrm{Cl})$ & MCS, $\beta(95 \% \mathrm{Cl})$ & SF-6D, $\beta(95 \% \mathrm{Cl})$ \\
\hline \multicolumn{4}{|c|}{$\begin{array}{l}\text { Number of comorbid chronic } \\
\text { diseases }^{a}\end{array}$} \\
\hline \multicolumn{4}{|l|}{0 (ref) } \\
\hline 1 & $-2.83^{\star \star \star}(-3.28,-2.38)$ & $\begin{array}{l}-1.46 * \star \star \star \\
-0.92)\end{array}$ & $\begin{array}{l}-0.030 * * *(-0.036 \\
-0.024)\end{array}$ \\
\hline 2 & $-7.37 \star \star \star ~(-7.96,-6.77)$ & $\begin{array}{l}-2.34 * \star \star *(-3.04 \\
-1.63)\end{array}$ & $\begin{array}{l}-0.063^{\star \star \star *}(-0.070 \\
-0.055)\end{array}$ \\
\hline 3 & $\begin{array}{l}-11.15^{\star \star *}(-11.95 \\
-10.36)\end{array}$ & $\begin{array}{l}-3.66 * \star \star \star \\
-2.71)\end{array}$ & $\begin{array}{l}-0.099 * \star \star \\
-0.089)\end{array}$ \\
\hline $3+$ & $\begin{array}{l}-14.29 * * *(-15.32 \\
-13.26)\end{array}$ & $\begin{array}{l}-6.34 * \star \star \\
-5.11)\end{array}$ & $\begin{array}{l}-0.138^{* * *}(-0.151 \\
-0.125)\end{array}$ \\
\hline \multicolumn{4}{|c|}{ Heart disease $^{a}$} \\
\hline \multicolumn{4}{|l|}{ No (ref) } \\
\hline Yes & $-5.09 * \star \star(-5.92,-4.25)$ & $\begin{array}{l}-3.39 * * \star(-4.33 \\
-2.46)\end{array}$ & $\begin{array}{l}-0.058 * * *(-0.068 \\
-0.048)\end{array}$ \\
\hline \multicolumn{4}{|c|}{ Circulatory disease $^{a}$} \\
\hline \multicolumn{4}{|l|}{ No (ref) } \\
\hline Yes & $-6.35^{\star \star \star}(-7.4,-5.29)$ & $\begin{array}{l}-4.33^{\star \star \star}(-5.51 \\
-3.15)\end{array}$ & $\begin{array}{l}-0.070 \star \star \star \star \\
-0.057)\end{array}$ \\
\hline \multicolumn{4}{|c|}{ Hypertension ${ }^{a}$} \\
\hline \multicolumn{4}{|l|}{ No (ref) } \\
\hline Yes & $-3.02 * \star \star(-3.49,-2.54)$ & $-0.83^{\star \star}(-1.36,-0.29)$ & $\begin{array}{l}-0.025^{\star \star *}(-0.031 \\
-0.019)\end{array}$ \\
\hline \multicolumn{4}{|c|}{ Type 1 diabetes ${ }^{a}$} \\
\hline \multicolumn{4}{|l|}{ No (ref) } \\
\hline Yes & $-4.00 * \star \star(-5.64,-2.37)$ & $-1.20(-3.04,0.63)$ & $-0.027 \star \star(-0.047,-0.007)$ \\
\hline \multicolumn{4}{|c|}{ Type 2 diabetes $^{a}$} \\
\hline \multicolumn{4}{|l|}{ No (ref) } \\
\hline Yes & $-3.02 * \star \star(-3.68,-2.37)$ & 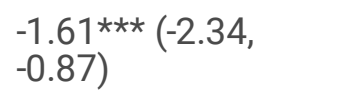 & $\begin{array}{l}-0.029 * * * *(-0.037 \\
-0.021)\end{array}$ \\
\hline \multicolumn{4}{|l|}{ Asthma $^{a}$} \\
\hline \multicolumn{4}{|l|}{ No (ref) } \\
\hline Yes & $-3.77 * \star \star(-4.32,-3.22)$ & $\begin{array}{l}-2.47 \star \star \star \\
-1.85)\end{array}$ & $\begin{array}{l}-0.041 * * *(-0.047 \\
-0.034)\end{array}$ \\
\hline Bronchitis & & & \\
\hline
\end{tabular}




\begin{tabular}{|c|c|c|c|}
\hline \multicolumn{4}{|c|}{ No (ref) } \\
\hline Yes & $-7.69 * \star \star(-8.93,-6.45)$ & $\begin{array}{l}-4.87 \star \star \star \\
-3.48)\end{array}$ & $\begin{array}{l}-0.078 * \star \star \\
-0.063)\end{array}$ \\
\hline \multicolumn{4}{|c|}{ Arthritis $^{a}$} \\
\hline \multicolumn{4}{|c|}{ No (ref) } \\
\hline Yes & $-8.5^{\star \star \star}(-8.98,-8.02)$ & $\begin{array}{l}-1.26 * \star \star \\
-0.69)\end{array}$ & $\begin{array}{l}-0.068 * \star \star \\
-0.061)\end{array}$ \\
\hline \multicolumn{4}{|c|}{ Cancer $^{a}$} \\
\hline \multicolumn{4}{|c|}{ No (ref) } \\
\hline Yes & $-4.08^{\star \star \star}(-5.12,-3.04)$ & $\begin{array}{l}-2.27 * \star \star \\
-1.10)\end{array}$ & $\begin{array}{l}-0.042 * * \star \\
-0.030)\end{array}$ \\
\hline
\end{tabular}

$\star * \star p<0.001, * * p<0.01, * p<0.05$; ref reference category.

a Model adjusted for age, gender, civil status, education, household income quintile, labour force status, race, place of living, smoking status, alcohol consumption, and physical activity

Table 4 summarizes the multiple regression analysis results for the number of comorbid chronic diseases which affect the SF-36 subscales. The results show that a negative correlation persists between comorbid chronic conditions and all the dimensions of SF-36. It indicates that a greater number of chronic diseases were associated with lower scores in all domains of the SF-36. For example, having more than three comorbid chronic conditions were associated with substantial reductions in PF (-26.76 units), RP (-41.67 units), RE (-25.36 units), SF (-25.02 units), MH (-9.87 units), VT (-19.92 units), BP (-29.33 units), and GH (-32.49 units).

Table 4. GEE estimates of the relationship between the status of chronic conditions and the dimensions of the SF-36 


\begin{tabular}{|c|c|c|c|c|c|c|c|c|}
\hline Variable & $\begin{array}{l}\begin{array}{l}\text { Physical } \\
\text { functioning, }\end{array} \\
\beta(95 \% \mathrm{Cl})\end{array}$ & $\begin{array}{l}\begin{array}{l}\text { Role } \\
\text { physical, }\end{array} \\
\beta(95 \% \\
\text { Cl) }\end{array}$ & $\begin{array}{l}\text { Role } \\
\text { emotional, } \\
\beta(95 \% \mathrm{Cl})\end{array}$ & $\begin{array}{l}\begin{array}{l}\text { Social } \\
\text { functioning, }\end{array} \\
\beta(95 \% \mathrm{Cl})\end{array}$ & $\begin{array}{l}\text { Mental } \\
\text { health, } \\
\beta(95 \% \\
\text { Cl) }\end{array}$ & $\begin{array}{l}\text { Vitality, } \\
\beta(95 \% \\
\text { Cl) }\end{array}$ & $\begin{array}{l}\text { Bodily } \\
\text { pain, } \\
\beta(95 \% \\
\text { Cl) }\end{array}$ & $\begin{array}{l}\text { General } \\
\text { health, } \\
\beta(95 \% \\
\text { Cl) }\end{array}$ \\
\hline \multicolumn{9}{|l|}{$\begin{array}{l}\text { Number } \\
\text { of } \\
\text { chronic } \\
\text { diseases }\end{array}$} \\
\hline \multicolumn{9}{|l|}{0 (ref) } \\
\hline \multirow[t]{2}{*}{1} & $-4.56^{\star \star \star}$ & $-7.87^{* \star \star}$ & $-4.55^{\star \star \star}$ & $-4.22^{\star \star \star}$ & $-2.94^{\star \star *}$ & $-4.23^{\star \star \star}$ & $-7.6^{\star \star \star \star}$ & $-7.12^{\star \star \star}$ \\
\hline & $\begin{array}{l}(-5.59 \\
-3.52)\end{array}$ & $\begin{array}{l}(-9.61 \\
-6.12)\end{array}$ & $\begin{array}{l}(-6.28 \\
-2.81)\end{array}$ & $\begin{array}{l}(-5.39 \\
-3.06)\end{array}$ & $\begin{array}{l}(-3.82 \\
-2.06)\end{array}$ & $\begin{array}{l}(-5.19 \\
-3.26)\end{array}$ & $\begin{array}{l}(-8.71 \\
-6.48)\end{array}$ & $\begin{array}{l}(-8.06 \\
-6.18)\end{array}$ \\
\hline \multirow[t]{2}{*}{2} & $-12.7^{\star \star \star}$ & $-20.84^{\star \star \star}$ & $-9.94 * \star \star$ & $-10.29 \star \star \star$ & $-4.69 * \star \star$ & $-8.86^{\star \star \star}$ & $-16.41^{\star \star \star}$ & $-15.27 * \star \star$ \\
\hline & $\begin{array}{l}(-14.06, \\
-11.34)\end{array}$ & $\begin{array}{l}(-23.13, \\
-18.55)\end{array}$ & $\begin{array}{l}(-12.21, \\
-7.67)\end{array}$ & $\begin{array}{l}(-11.81 \\
-8.76)\end{array}$ & $\begin{array}{l}(-5.84 \\
-3.55)\end{array}$ & $\begin{array}{l}(-10.12 \\
-7.59)\end{array}$ & $\begin{array}{l}(-17.87 \\
-14.95)\end{array}$ & $\begin{array}{l}(-16.5 \\
-14.05)\end{array}$ \\
\hline \multirow[t]{2}{*}{3} & 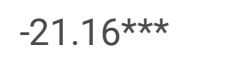 & $-30.96 * \star \star$ & 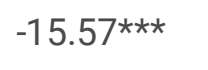 & $-16.37 \star \star \star$ & $-7.44^{\star \star \star}$ & $-13.05^{\star \star \star}$ & $-22.96 * \star \star$ & 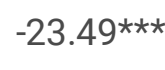 \\
\hline & $\begin{array}{l}(-22.99, \\
-19.33)\end{array}$ & $\begin{array}{l}(-34.04 \\
-27.88)\end{array}$ & $\begin{array}{l}(-18.63, \\
-12.52)\end{array}$ & $\begin{array}{l}(-18.42, \\
-14.32)\end{array}$ & $\begin{array}{l}(-8.98 \\
-5.89)\end{array}$ & $\begin{array}{l}(-14.75, \\
-11.35)\end{array}$ & $\begin{array}{l}(-24.92, \\
-20.99)\end{array}$ & $\begin{array}{l}(-25.14 \\
-21.84)^{\prime}\end{array}$ \\
\hline \multirow[t]{2}{*}{$3+$} & $-26.76^{\star \star \star}$ & 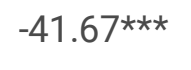 & $-25.36^{\star \star \star}$ & 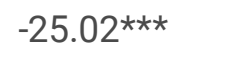 & $-9.87^{\star \star \star}$ & 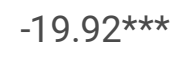 & $-29.33^{\star \star \star}$ & $-32.49 * * \star$ \\
\hline & $\begin{array}{l}(-29.13, \\
-24.4)\end{array}$ & $\begin{array}{l}(-45.66, \\
-37.68)\end{array}$ & $\begin{array}{l}(-29.32, \\
-21.41)\end{array}$ & $\begin{array}{l}(-27.68, \\
-22.36)\end{array}$ & $\begin{array}{l}(-11.87 \\
-7.87)\end{array}$ & $\begin{array}{l}(-22.12, \\
-17.71)\end{array}$ & $\begin{array}{l}(-31.88, \\
-26.78)\end{array}$ & $\begin{array}{l}(-34.62 \\
-30.35)\end{array}$ \\
\hline
\end{tabular}

Model adjusted for age, gender, civil status, education, household income quintile, labour force status, race, place of living, smoking status, alcohol consumption, and physical activity

$\star \star \star \star p<0.001, * \star p<0.01, * p<0.05$; ref reference category.

\section{Discussion}

This study is the first to assess the relationships between comorbid chronic diseases and HRQoL among the obese population in Australia. The current study further highlighted the interplay of nine chronic diseases in the previously found association between obesity and HRQoL $[6,14]$.

The study results showed that the PCS, MCS, and SF-6D scores in obese people reduced sharply with an increasing number of chronic diseases. The negative association between the rising number of comorbid chronic conditions and overall HRQoL is similar to previous studies that reported a significant reduction in HRQoL among persons having multimorbidities $[9,26,30-35]$. The results showed that obese individuals having any of the nine studied chronic diseases were associated with reduced PCS, MCS, and SF-6D scores. Results from previous empirical studies showed that an increase of the number of comorbidities in an individual or patient was associated with lower HRQoL [23, 25, $27,28]$, which is consistent with the current study findings. Also, earlier studies have reported a statistically significant negative association between a higher number of comorbid chronic conditions and worse scores on PCS and MCS in obese people [30,36]. Further, this current study revealed that a higher number of chronic diseases was associated with a reduction in scores in all eight dimensions of the SF-36. Similar findings have been highlighted elsewhere that studied the association between comorbid diseases and HRQoL [37-39]. 
Although consistent findings were revealed, some of the earlier studies used a different survey instrument other than the SF-36 to measure HRQoL $[31,32,34,35]$. Therefore, there is a need for careful interpretation of the current study findings compared with the previous literature. The current results indicate that the burden posed by comorbid chronic diseases in an individual irrespective of the underlying condition, and the association could be attributed to several plausible factors. First, the observed lower HRQoL could be due to the synergistic effects that coexist among chronic diseases, resulting from one condition hampering a patient's ability to adhere to treatment for another [40]. An additional reason could be that obese individuals are at a greater risk of developing several chronic cardiovascular, muscular-skeletal, and metabolic comorbid conditions [41,42]. As a result, these conditions in the obese population could have negated their quality of life due to the increasing deteriorating effects of multiple chronic diseases [9]. Besides, comorbidities may profoundly impact patients' ability to manage their self-care and may pose significant barriers to lifestyle changes and regimen adherence [38]. Further, the present study results could have been influenced by comorbid mental health disorders that are most prevalent among persons suffering from chronic diseases.

The present study has several strengths. Firstly, this is the first longitudinal study that reports the relationships between comorbid chronic diseases and HRQoL in obese populations by analyzing eight dimensions, summary measures (PCS and MCS), and the health utility index (SF-6D) of the SF-36. Secondly, this study considered nine chronic diseases to check their associations separately with HRQoL. The current study was not without limitations, however. The unbalanced longitudinal nature of the study prevents the establishment of causal associations. Secondly, the study is limited in generalizability because the study's sample was limited to only the Australian obese population, which might portray features different from those in other countries and settings. Data on the severity of the comorbid conditions were not available, and this could have played a role in determining the association with HRQoL.

The study's findings provide first-hand evidence on the impact of increasing comorbid chronic diseases on the HRQoL of obese adults. The significant association found in the current study has implications for strengthening public health measures. Preventive measures are needed to reduce the burden of obesity and the subsequent development of obesity-related comorbidities. More comprehensive and holistic care should be given to individuals with chronic diseases due to the burden associated with its complications. Clinically, the types of comorbid chronic conditions found in the study related to HRQoL should inform treatment and care strategies to be deployed for persons with obesity.

\section{Conclusions}

The present study provides a better understanding of the relationship between comorbid chronic diseases and HRQoL in obese people in Australia. The study demonstrates that comorbid chronic disease in obese individuals is associated with poorer HRQoL. More specifically, increasing the number of comorbid chronic conditions was associated with a further reduction in scores for all eight dimensions, summary measures (PCS and MCS), and health utility index (SF6D) of the SF-36. The findings, therefore, call for improved holistic management of obesity and all obesity-related comorbidities.

\section{Abbreviations}

BMI Body Mass Index

HILDA Household, Income and Labour Dynamics in Australia Survey

HRQoL Health-related Quality of Life

Page 14/19 
PCS Physical Component Summary

MCS Mental Component Summary

SF-6D Short-Form Six-Dimension

SF-36 36-Item Short-Form Health Survey

\section{Declarations}

\section{Authors' contributions}

SAK initiated the study, conducted the data analysis. SAK, BOA, MS, RGA, and AAS drafted the manuscript. KA, JG and SB offered advice, critical comments and edited the draft manuscript. All the authors read and approved the final manuscript.

\section{Ethics approval}

This paper uses unit record data from Household, Income and Labour Dynamics in Australia Survey (HILDA) conducted by the Australian Government Department of Social Services (DSS). However, the findings and views reported in this paper are those of the authors and should not be attributed to the Australian Government, DSS, or any of DSS contractors or partners. DOI: 10.26193/OFRKRH, ADA Dataverse, V2."

This study did not require ethical approval as the analysis used only de-identified existing unit record data from the HILDA survey. However, the authors completed and signed the Confidentiality Deed Poll and sent it to NCLD (ncldresearch@dss.gov.au) and ADA (ada@anu.edu.au) before the data applications' approval. Therefore, the datasets analysed and/or generated during the current study are subject to the signed confidentiality deed.

\section{Conflict of interest}

The authors declare that they have no conflicts of interest.

\section{Availability of data and materials}

The data used for the study was collected from the Melbourne Institute of Applied Economic and Social Research. There are some restrictions on this data and it is not available to the public. Those interested in accessing this data should contact the Melbourne Institute of Applied Economic and Social Research, The University of Melbourne, VIC 3010, Australia.

\section{Funding}

This research did not receive any specific grant from funding agencies in the public, commercial or not-for-profit sectors.

\section{References}

1. World Health Organization (WHO). (2020). Obesity and overweight. Retrieved August 19, 2020, from https://www.who.int/news-room/fact-sheets/detail/obesity-and-overweight

2. Hayes, A. J., Lung, T. W. C., Bauman, A., \& Howard, K. (2017). Modelling obesity trends in Australia: Unravelling the past and predicting the future. International Journal of Obesity, 41(1), 178-185. doi:10.1038/ijo.2016.165 
3. Australian Bureau of Statistics. (2018). National Health Survey: first results, 2017-18. ABS cat. no. 4364.0.55.001. Canberra: ABS.

4. Klassen, A., Wickert, N., Tsangaris, E., Klaassen, R., \& Anthony, S. (2017). Health-Related Quality of Life (pp. 735747). doi:10.1007/978-3-319-33679-4_30

5. Perales, F., del Pozo-Cruz, J., del Pozo-Cruz, J., \& del Pozo-Cruz, B. (2014). On the associations between physical activity and quality of life: findings from an Australian nationally representative panel survey. Quality of Life Research, 23(7), 1921-1933. doi:10.1007/s11136-014-0645-4

6. Busutil, R., Espallardo, O., Torres, A., Martínez-Galdeano, L., Zozaya, N., \& Hidalgo-Vega, Á. (2017). The impact of obesity on health-related quality of life in Spain. Health and Quality of Life Outcomes, 15(1), 197. doi:10.1186/s12955-017-0773-y

7. Kortt, M. A., \& Dollery, B. (2011). Association Between Body Mass Index and Health-Related Quality of Life Among an Australian Sample. Clinical Therapeutics, 33(10), 1466-1474. doi:10.1016/j.clinthera.2011.08.009

8. Schelbert, K. B. (2009). Comorbidities of Obesity. Primary Care: Clinics in Office Practice, 36(2), 271-285. doi:10.1016/j.pop.2009.01.009

9. Ul-Haq, Z., Mackay, D. F., Fenwick, E., \& Pell, J. P. (2012). Impact of metabolic comorbidity on the association between body mass index and health-related quality of life: a Scotland-wide cross-sectional study of 5,608 participants. BMC Public Health, 12(1), 143. doi:10.1186/1471-2458-12-143

10. Zhu, Y., Wang, Q., Pang, G., Lin, L., Origasa, H., Wang, Y., ... Shi, H. (2015). Association between Body Mass Index and Health-Related Quality of Life: The "Obesity Paradox" in 21,218 Adults of the Chinese General Population. PLOS ONE, 10(6), e0130613. doi:10.1371/journal.pone.0130613

11. Schienkiewitz, A., Mensink, G. B. M., \& Scheidt-Nave, C. (2012). Comorbidity of overweight and obesity in a nationally representative sample of German adults aged 18-79 years. BMC Public Health, 12(1). doi:10.1186/14712458-12-658

12. Guh, D. P., Zhang, W., Bansback, N., Amarsi, Z., Birmingham, C. L., \& Anis, A. H. (2009). The incidence of comorbidities related to obesity and overweight: A systematic review and meta-analysis. BMC Public Health, 9, 1-20. doi:10.1186/1471-2458-9-88

13. Audureau, E., Pouchot, J., \& Coste, J. (2016). Gender-Related Differential Effects of Obesity on Health-Related Quality of Life via Obesity-Related Comorbidities. Circulation: Cardiovascular Quality and Outcomes, 9(3), 246256. doi:10.1161/CIRCOUTCOMES.115.002127

14. Jia, H., \& Lubetkin, E. I. (2005). The impact of obesity on health-related quality-of-life in the general adult US population. Journal of Public Health, 27(2), 156-164. doi:10.1093/pubmed/fdi025

15. Kolotkin, R. L., Crosby, R. D., Williams, G. R., Hartley, G. G., \& Nicol, S. (2001). The relationship between healthrelated quality of life and weight loss. Obesity Research, 9(9), 564-571. doi:10.1038/oby.2001.73

16. Renzaho, A., Wooden, M., \& Houng, B. (2010). Associations between body mass index and health-related quality of life among Australian adults. Quality of Life Research, 19(4), 515-520. doi:10.1007/s11136-010-9610-z

17. Song, H. J., Lee, E. K., \& Kwon, J. W. (2015). Gender Differences in the Impact of Obesity on Health-Related Quality of Life. Asia-Pacific Journal of Public Health, 28(2), 146-156. doi:10.1177/1010539515626267

18. Kortt, M. A., \& Clarke, P. M. (2005). Estimating Utility Values for Health States of Overweight and Obese Individuals Using the SF-36. Quality of Life Research, 14(10), 2177-2185. doi:10.1007/s11136-005-8027-6

19. Kolotkin, R. L., \& Andersen, J. R. (2017). A systematic review of reviews: exploring the relationship between obesity, weight loss and health-related quality of life. Clinical Obesity, 7(5), 273-289. doi:10.1111/cob.12203 
20. Rozjabek, H., Fastenau, J., Laprade, A., \& Sternbach, N. (2020). Adult obesity and health-related quality of life, patient activation, work productivity, and weight loss behaviors in the United States. Diabetes, Metabolic Syndrome and Obesity: Targets and Therapy, 13, 2049-2055. doi:10.2147/DMSO.S245486

21. Pimenta, F. B. C., Bertrand, E., Mograbi, D. C., Shinohara, H., \& Landeira-Fernandez, J. (2015). The relationship between obesity and quality of life in Brazilian adults. Frontiers in Psychology, 6(July), 1-7. doi:10.3389/fpsyg.2015.00966

22. Slagter, S. N., Van Vliet-Ostaptchouk, J. V., Van Beek, A. P., Keers, J. C., Lutgers, H. L., Van Der Klauw, M. M., \& Wolffenbuttel, B. H. R. (2015). Health-Related quality of life in relation to obesity grade, type 2 diabetes, metabolic syndrome and inflammation. PLOS ONE, 10(10), 1-17. doi:10.1371/journal.pone.0140599

23. Banegas, J. R., López-García, E., Graciani, A., Guallar-Castillón, P., Gutierrez-Fisac, J. L., Alonso, J., \& RodríguezArtalejo, F. (2007). Relationship between obesity, hypertension and diabetes, and health-related quality of life among the elderly. European Journal of Cardiovascular Prevention \& Rehabilitation, 14(3), 456-462. doi:10.1097/HJR.0b013e3280803f29

24. Choo, J., Jeon, S., \& Lee, J. (2014). Gender differences in health-related quality of life associated with abdominal obesity in a Korean population. BMJ Open, 4(1), 1-8. doi:10.1136/bmjopen-2013-003954

25. Lima, M. G., De Azevedo Barros, M. B., César, C. L. G., Goldbaum, M., Carandina, L., \& Ciconelli, R. M. (2009). Impact of chronic disease on quality of life among the elderly in the state of Sao Paulo, Brazil: A population-based study. Revista Panamericana de Salud Publica/Pan American Journal of Public Health, 25(4), 314-321. doi:10.1590/S1020-49892009000400005

26. Tyack, Z., Kuys, S., Cornwell, P., Frakes, K.-A., \& McPhail, S. (2018). Health-related quality of life of people with multimorbidity at a community-based, interprofessional student-assisted clinic: Implications for assessment and intervention. Chronic Illness, 14(3), 169-181. doi:10.1177/1742395317724849

27. Zhang, L., Lix, L. M., Ayilara, O., Sawatzky, R., \& Bohm, E. R. (2018). The effect of multimorbidity on changes in health-related quality of life following hip and knee arthroplasty. The Bone \& Joint Journal, 100-B(9), 1168-1174. doi:10.1302/0301-620X.100B9.BJJ-2017-1372.R1

28. Busetto, L., Pilone, V., Schettino, A. M., Furbetta, N., Zappa, M., Di Maro, A., ... Italian Group for Lap-Band. (2012). Determinants of health-related quality of life in morbid obese candidates to gastric banding. Eating and weight disorders: $E W D, 17(2)$, e93-100. doi:10.3275/8244

29. Hoare, E., Crooks, N., Hayward, J., Allender, S., \& Strugnell, C. (2019). Associations between combined overweight and obesity, lifestyle behavioural risk and quality of life among Australian regional school children: Baseline findings of the Goulburn Valley health behaviours monitoring study. Health and Quality of Life Outcomes, 17(1), 1-10. doi:10.1186/s12955-019-1086-0

30. Sundh, J., Johansson, G., Larsson, K., Lindén, A., Löfdahl, C.-G., Janson, C., \& Sandström, T. (2015). Comorbidity and health-related quality of life in patients with severe chronic obstructive pulmonary disease attending Swedish secondary care units. International journal of chronic obstructive pulmonary disease, 10, 173-83. doi:10.2147/COPD.S74645

31. Brettschneider, C., Leicht, H., Bickel, H., Dahlhaus, A., Fuchs, A., Gensichen, J., ... König, H.-H. (2013). Relative Impact of Multimorbid Chronic Conditions on Health-Related Quality of Life - Results from the MultiCare Cohort Study. PLOS ONE, 8(6), e66742. doi:10.1371/journal.pone.0066742

32. Hunger, M., Thorand, B., Schunk, M., Döring, A., Menn, P., Peters, A., \& Holle, R. (2011). Multimorbidity and healthrelated quality of life in the older population: results from the German KORA-Age study. Health and Quality of Life Outcomes, 9(1), 53. doi:10.1186/1477-7525-9-53 
33. Serrano-Aguilar, P., Muñoz-Navarro, S. R., Ramallo-Fariña, Y., \& Trujillo-Martín, M. M. (2009). Obesity and health related quality of life in the general adult population of the Canary Islands. Quality of Life Research, 18(2), 171177. doi:10.1007/s11136-008-9427-1

34. Sendi, P., Brunotte, R., Potoczna, N., Branson, R., \& Horber, F. F. (2005). Health-Related Quality of Life in Patients with Class II and Class III Obesity. Obesity Surgery, 15(7), 1070-1076. doi:10.1381/0960892054621323

35. Wang, J.-W., Sun, L., Ding, N., Li, J., Gong, X.-H., Chen, X.-F., ... Yu, J.-M. (2016). The association between comorbidities and the quality of life among colorectal cancer survivors in the People's Republic of China. Patient Preference and Adherence, 10, 1071. doi:10.2147/PPA.S100873

36. Marrie, R. A., Horwitz, R., Cutter, G., \& Tyry, T. (2012). Cumulative impact of comorbidity on quality of life in MS. Acta Neurologica Scandinavica, 125(3), 180-186. doi:10.1111/j.1600-0404.2011.01526.x

37. Pati, S., Pati, S., Akker, M. van den, Schellevis, F. (François) G., Jena, S., \& Burgers, J. S. (2020). Impact of comorbidity on health-related quality of life among type 2 diabetic patients in primary care. Primary Health Care Research \& Development, 21, e9. doi:10.1017/S1463423620000055

38. Adriaanse, M. C., Drewes, H. W., van der Heide, I., Struijs, J. N., \& Baan, C. A. (2016). The impact of comorbid chronic conditions on quality of life in type 2 diabetes patients. Quality of Life Research, 25(1), 175-182. doi:10.1007/s11136-015-1061-0

39. Mond, J. M., \& Baune, B. T. (2009). Overweight, Medical Comorbidity and Health-related Quality of Life in a Community Sample of Women and Men. Obesity, 17(8), 1627-1634. doi:10.1038/oby.2009.27

40. Mujica-Mota, R. E., Roberts, M., Abel, G., Elliott, M., Lyratzopoulos, G., Roland, M., \& Campbell, J. (2015). Common patterns of morbidity and multi-morbidity and their impact on health-related quality of life: evidence from a national survey. Quality of Life Research, 24(4), 909-918. doi:10.1007/s11136-014-0820-7

41. Cercato, C., \& Fonseca, F. A. (2019). Cardiovascular risk and obesity. Diabetology \& Metabolic Syndrome, 11(1), 74. doi:10.1186/s13098-019-0468-0

42. Choi, S., Kim, K., Kim, S. M., Lee, G., Jeong, S.-M., Park, S. Y., ... Park, S. M. (2018). Association of Obesity or Weight Change With Coronary Heart Disease Among Young Adults in South Korea. JAMA Internal Medicine, 178(8), 1060. doi:10.1001/jamainternmed.2018.2310

\section{Figures}

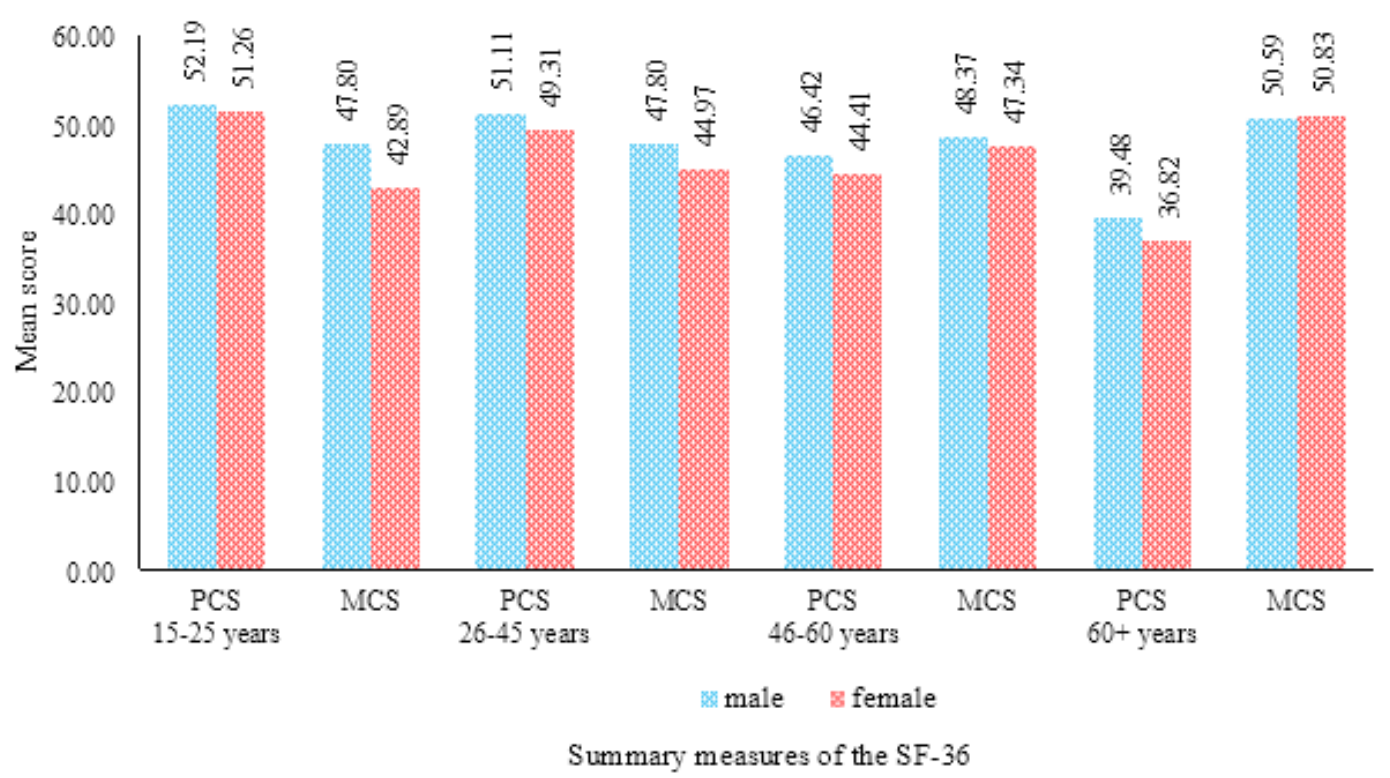

Page 18/19 


\section{Figure 1}

Mean summary measures of the SF-36 (PCS and MCS) by age and gender

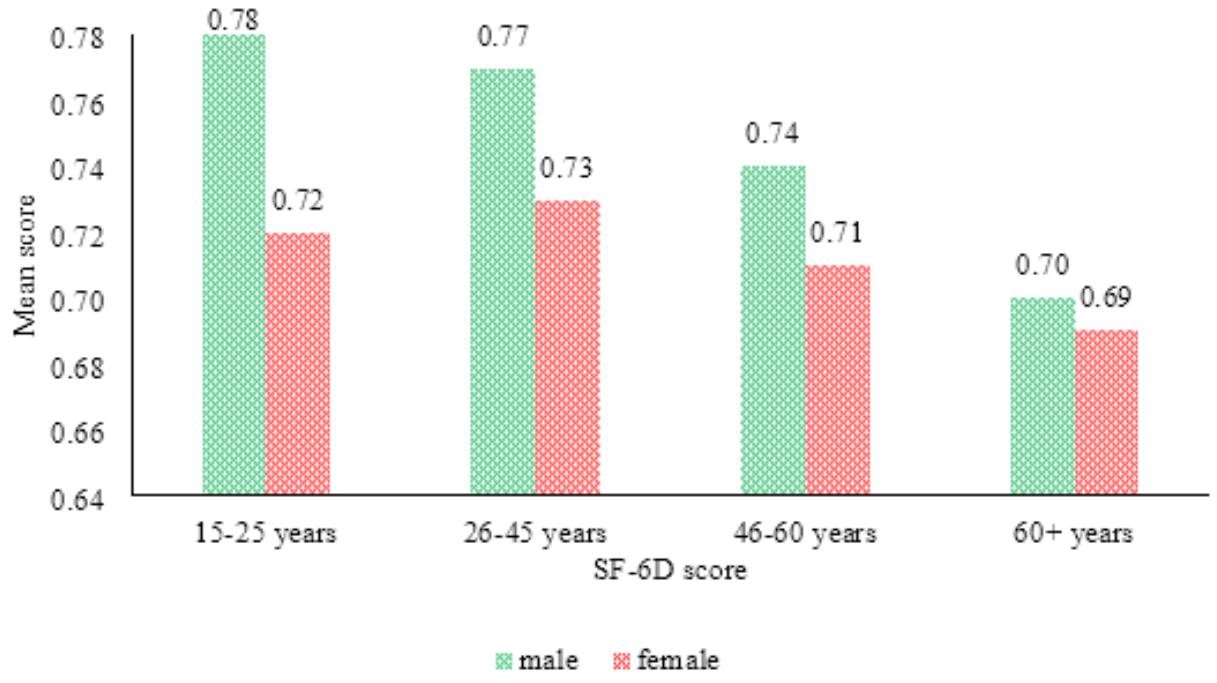

Figure 2

Mean SF-6D score by age and gender 